\title{
$\bullet$ \\ Industry-Ready Active Packaging Technologies in Food Sector
}

\section{IJCRR}

Section: Healthcare

ISI Impact Factor

(2019-20): 1.628

IC Value (2019): 90.81

$\operatorname{SJIF}(2020)=7.893$

(c) (7) (8)

Copyright@IJCRR

\section{Arumugam Siddhu Adhiaman ${ }^{1 *}$, Kulathooran Ramalakshmi², Dhanraj Madhushalini3}

'Assistant Manager, Department of Storage and Marketing, National Bank for Agriculture and Rural Development (NABARD), Bhopal, Madhya Pradesh, India; ${ }^{23}$ Department of Food Technology, Rajalakshmi Engineering College, Chennai, India.

\section{ABSTRACT}

Food packaging aims to deliver food to the consumer in a sound state. A good food package aims to preserve food commodities from external spoilage factors. With the evolution of Industry 4.0, active packaging food technologies take a leap towards nextgeneration technology with artificial intelligence and big data in the food sector. The main functions of a common food packaging element comprise containment, convenience, communication and cost. In recent days, the purpose goes beyond this. Active packaging is a fast-growing food packaging technology in which the additives are incorporated into the packaging layer of primary food so that the desired preservation effect is achieved with high efficiency. Active packaging is a modern technology that aims to benefit food manufacturers by helping them to deliver high-quality natural food without any artificial additives added to the primary food item to their consumers. The incorporated additives may be in the form of moisture absorbers, antimicrobial agents, oxygen scavengers, ethylene absorbers etc. In this review article the basic active packaging technology, its uses, procedure, advantages, limitations are discussed from an industry perspective.

Key Words: Artificial Intelligence, Efficiency, Incorporation, Industry 4.0, Procedure, Manufacturing, Natural food

\section{INTRODUCTION}

Packaging technology gives food manufacturers a strategic advantage in the market. Packaging normally protects the food from external factors like moisture, microorganisms, heat, light, foreign matter, unwanted gases etc. Packaging is the technology that protects the food from external factors and delivers the food to the consumers in a sound state. The main role of food packaging is to protect the food from the outside environment, to prevent cross-contamination; to make consumers informed choices about the nutrition of the food that has been packed. Many packaging technologies have been developed to meet the quality requirements of foods like modified atmospheric packaging, controlled atmospheric packaging, vacuum packaging and so on. Packaging is also a marketing factor. It also influences logistics and distribution in the supply chain. Nowadays the design of the packaging material is given importance among all the factors as this plays a vital role in cost-cutting measures.

Traditional packaging technology provides only a barrier against the external environment conditions, but not in the preservation of the food in contact. On the other hand, active packaging besides protecting the food from the external environment also gives the packed food a preservation effect owing to the active principle components used in the technology. As the growth of convenience food is increasing with pace and subsequent increase in e-commerce, the food industry is demanding novel packing technologies that provide a one-stop solution for food packaging.

\section{FOOD PACKAGING MATERIALS}

According to the nature of the food to be preserved, there are many types of packaging material available in the market. Primary packaging material is one in which the food will be in direct contact with the packaging material, whereas secondary package refers to the packaging material that covers the primary packed food. Mostly secondary packages are used for wholesale and institutional supplies. Many packaging materials like steel cans, aluminium cans, polypropylene, polyethene, polyolefin, polyethene terephthalate, glass, polycarbonate, polyvinyl acetate (PVA), Fluoropolymers, Cellulose-based

\section{Corresponding Author:}

Arumugam Siddhu Adhiaman, Assistant Manager, Department of Storage and Marketing, National Bank for Agriculture and Rural Development (NABARD), Bhopal, Madhya Pradesh, India; Ph: 9489634545; Email: siddhuadiaman@gmail.com/siddhuadhiaman.a@rajalakshmi.edu.in

ISSN: 2231-2196 (Print)

Received: 24.02 .2021
ISSN: 0975-5241 (Online)

Revised: 12.03 .2021
Accepted: 15.06.2021
Published: 20.11 .2021 
materials, High nitrile polymers, polyvinylidene chloride, polystyrene, acrylonitrile butadiene styrene, polyamide, ethylene vinyl alcohol, ethylene-vinyl acetate (EVA), styrene-butadiene are being used in the food industry.

Due to low cost and good barrier properties against various physical, chemical and biological factors, polyethene films are widely employed in the food industry. The main disadvantage of polyethene material is that it is chemically inert which makes its use in active packaging technology on a limited scale. This forces the technologists to make some changes to this material in the form of pre-treatments to create an active environment and in turn, produces better results. Some of the methods for modification are plasma, UV and wet chemical treatments. ${ }^{1}$

\section{ACTIVE PACKAGING TECHNOLOGY}

Active packaging is sometimes called interactive packaging. Active components can be incorporated into the packages in the form of sachets, pouches, patches and so on. Research on intelligent labelling systems is given importance to bring in more innovations in food packaging. Active packaging materials interact with the headspace gases and also make a compatible environment with the food inside the package either in form of antioxidants or antimicrobial agents. The direct addition of any preservative either a chemical preservative like nitrates, sorbates or a bacteriocin such as a nisin to the food may alter the nature of the food to a certain extent. ${ }^{2}$ Also the efficacy rate of the added chemicals may vary and in some cases even produce undesirable effects. To overcome this, a new promising method of food packaging is employed in the food industry. Active packaging is adding or incorporating the additives on the food packaging layer or in the headspace of the primary food so that direct contact between the food and preservative are avoided. ${ }^{3}$ It aims to reduce or remove the use of chemical preservatives, to add more hurdles to increase the package efficiency. Active packaging can be synergistically combined with other packing techniques such as MAP (Modified Atmospheric Packaging) and CAP (Controlled Atmospheric Packaging) to improve the preservation effect and package efficiency.

\section{Table 1: Active Components in Active systems}

$\begin{array}{ll}\text { Active System } & \text { Components used } \\ \mathrm{CO}_{2} \text { Emitters } & \text { Iron powder - Calcium Hydrox- } \\ & \text { ide, Ferrous Carbonate - Metal- } \\ & \text { lic halide }\end{array}$

Ethylene Absorbers

Activated Charcoal, Silica gel - Potassium Permanganate, Fullers earth

Ethanol Emitters
Antimicrobial Emitters

Antioxidant Releasing agents

Anti-fogging / Anti sticking agents

Light absorbing / regulators

Moisture Absorbing

Gas permeable agents

Oxygen Scavengers

One of the commonly used subcategories of active packaging technology is the oxygen scavengers in food products, especially in meat-based foods. Ferrous oxide is one of the most used elements for scavenging oxygen in the food industry. Oxygen absorbers possess various inhibitory mechanisms to stop the oxidation chain reaction. ${ }^{4}$ They also prevent discolouration of fresh meat and keep out the pests. Oxygen scavengers are most widely used in meat packages where the chance of quality deterioration is high due to oxygen. In addition to metallic oxygen scavengers, some of the nonmetallic based scavengers like ascorbic acid and their derivatives are also used in the industry for scavenging the oxygen in food items. In some systems, oxygen scavengers are based on an enzymatic base (usually with glucose oxidase or ethanol oxidase) which are added in the form of sachets and also directly fortified into the layer of the package.

\section{Carbon dioxide scavengers / emitters}

Certain food products like roasted coffee, beef jerky are prone to damage by produced carbon dioxide. $\mathrm{CO}_{2}$ absorberscanbebasedonsodiumhydroxideandcalciumbased organic components. ${ }^{5}$ Package bursts can be prevented by using Carbon dioxide emitters. Roasted coffee in a fresh state can release considerable amounts of carbon dioxide due to the reaction called Strecker degradation between sugars and amines. The generated carbon dioxide can make the packaging burst due to an increase in internal pressure. The carbon dioxide has to be removed from the package to extend its shelf life and to ensure the aroma of the roasted coffee is not vaporized. A formula comprising and activated charcoal and calcium oxide is used in Polyethylene coffee pouches to inhibit the $\mathrm{CO}_{2}$ but nowadays combined oxygen and carbon dioxide scavenger sachets are commercially used for canned and foil pouched coffees in Japan and the USA. ${ }^{6}$ These dualpurpose sachets contain iron powder for scavenging oxygen and calcium hydroxide for scavenging carbon dioxide where it is converted to calcium carbonate under high humidity conditions. ${ }^{3}$ Usually carbon dioxide absorbers are of two types - containing physical absorbents like zeolite and a chemical absorbent like Calcium hydroxide. Carbon dioxide, if present in excess inside the package also bursts at one 
point causing the burst of the food package. $\mathrm{CO}_{2}$ scavengers are used in the form of sachets in food products.

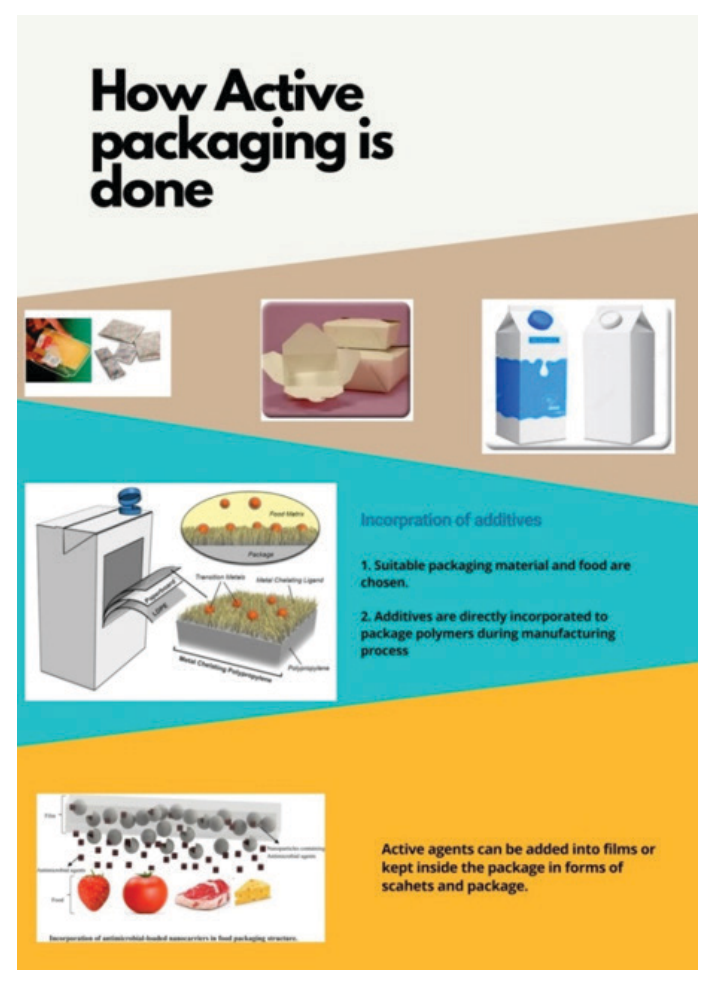

Figure 1: Active Packaging Process.

\section{Ethylene Scavengers}

Ethylene is a plant growth regulator responsible for the process of ripening horticultural commodities like flowers, fruits and vegetables. The effect of ethylene is very much important in each and every stage of development of fruits and vegetables. The various stages of development includes flowering, development of colours in certain fruits and vegetables, root production stimulation, bitter flavour development etc., ${ }^{7}$ During the supply chain, the effect of ethylene should be suppressed or controlled so that the ripening process is delayed during transit. To suppress the effect of ethylene, food industries are using ethylene scavengers in the package lot (individual/bulk). As a result, the ripening takes place once the commodity is near to the consumer in the supply chain and not before that. This technology greatly reduces the losses of horticultural commodities during transportation and fetches good returns to the industry. ${ }^{8}$ Most of the ethylene absorbers used in the food industry are based on potassium permanganate ( $\mathrm{KMnO} 4)$. The oxidation of the ethylene into ethanol and acetate by Potassium permanganate will induce a colour change to brown from purple indicating the available scavenging capacity of ethylene. Potassium permanganate-based ethylene scavengers can be used both for the retail package as well as can be used in warehouse or packhouses that has facilities for storing fruits for long term storage. The forms in which the scavengers can be employed are sachets, embedded paper bags or any other such provisions suitable.

Table 2: Commercial Active Systems

\begin{tabular}{lll}
$\begin{array}{l}\text { Trade } \\
\text { Name }\end{array}$ & Company & Type \\
Freshlock & Mitsubishi - Japan & $\mathrm{CO}_{2}$ Scavengers \\
Verifrais & Codimer France & $\mathrm{CO}_{2}$ Scavengers \\
Vitalon G & Toagosei Japan & $\mathrm{CO}_{2}$ Scavengers \\
Ageless & Mitsubishi - Japan & Oxygen scavenger \\
Freshhilizer & Toppan - Japan & Oxygen scavenger \\
Bioka & Bioka - Finland & Oxygen scavenger \\
Dri - Loc & Sealand -USA & Moisture Absorber \\
Tender Pac & Seal Pac - Germany & Moisture Absorber \\
Bio master & Addmaster - USA & Antimicrobial Packaging \\
SANICO & Laboratories & Antifungal Coating \\
& STANDA & \\
\hline
\end{tabular}

\section{Ethanol Emitters}

In contrast to the ethylene absorbers to absorb excess ethylene produced to influence the ripening of the horticultural commodities, ethanol emitters are substances that have antimicrobial properties and are particularly effective against moulds. They can also inhibit bacterial and yeast growth. Research has been made on the preservation effects of ethanol on most commonly used food articles to extend their shelf life. ${ }^{9}$ It has been proven that sachets containing ethanol or ethanol incorporated packaging films have a good preservation effect against the spoilage moulds specifically at a concentration of above $90 \%$. Ethanol is encapsulated in silicon dioxide to achieve a slow-release of ethanol vapour. Ethanolbased sachets and films are to be customized according to the nature of the food item to be packed. When food is packed with an ethanol-emitting sachet, the food absorbs moisture and releases ethanol vapour and spreads into the headspace package.

\section{Flavour absorbers}

Certain chemical and biochemical reactions inside the food matrix results in the production of off and undesirable odours due to the breakdown products consisting of fatty acids, amines, aldehydes and ketones. Oxidation usually produces off odours indicating the deteriorative quality of the food to the consumer. Some unpleasant odours can be sensed by consumers when the package is opened, although the food appears to be safe. ${ }^{10}$ Plastic processing like moulding, extrusion also can lead to off flavours. Antioxidants can also be used to decrease unpleasant odours. Undesirable flavour scalping of desirable food components can be done using the flavour absorbers. Also bitter and undesirable astringent components can be removed by using these types of absorbers. Dupont's Odour and Taste Control (OTC) technology 
claims the removal of aldehydes such as hexanal and heptanal from package headspaces. In certain foods where flavour and aroma are desirable as in the case of horticultural crops like aromatic flowers, distinctive aromas are slowly released upon opening the packet by using suitable technology. ${ }^{11}$ Flavour and aroma emitters give a pleasant sensation to the consumers indicating the freshness of the particular food, although the food has been packed a long ago. Some commercially available products are ABSCENTS, AROMACAN, SINCERA etc.

\section{Antimicrobial films}

Antimicrobials are substances that are based either on natural sources like herbs, plant extracts or artificial sources like food additives. ${ }^{12}$ Antimicrobial food additives can be incorporated directly onto the food packages to reduce the growth of spoilage microorganisms in the food items. Antimicrobial packaging helps to extend the lag phase and reduced the growth rate of microbes resulting in prolonged shelf life and better food safety. Antimicrobial active packaging film releases the antimicrobial agent on the food and maintains its concentration on the food surface above the minimum inhibitory concentration for the target microorganism. They are applied mostly on bakery, cheese, meat and fish products and also some horticultural commodities. The antimicrobial agent incorporation into the food polymer is done using a solvent casting method. It has been shown that antimicrobial incorporated food packages stop the growth of pathogenic microorganisms in the food. Antimicrobial agents may include essential oils, herbal extracts, and natural plant substances and so on. ${ }^{13}$ Proper coating methods and controlled release of the incorporated agents are crucial factors in attaining effective results. Antimicrobial films are usually made by incorporating one of the active components having antimicrobial properties either from plant animals or any other source. In the food industry, antimicrobial additive components are directly incorporated into the polymer matrix to improve the efficiency of preservation. Normal antimicrobial components incorporated are organic acids, herbal extracts, spice extracts, chelating agents, antifungal agents etc., To design a green and sustainable food package, antimicrobial agents can be used along with biodegradable substances.

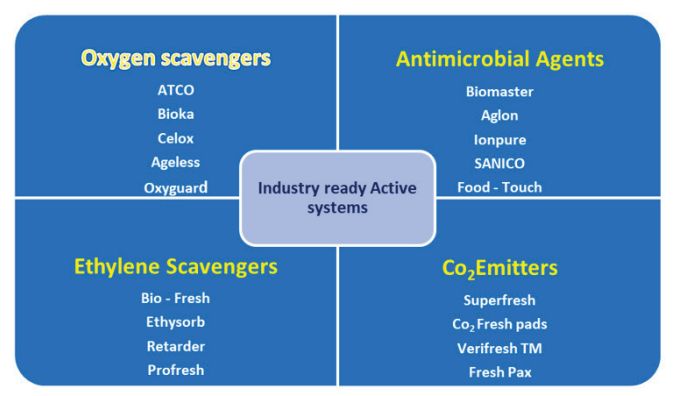

Figure 2: Commercially Available systems.

\section{Antioxidant films}

Fat and oil-containing food items are highly prone to oxidation reaction via a free radical process. This undesirable reaction in fat and fat-containing food items produce off odours and rancid flavours due to the formation of aldehydes and their breakdown products. In dried foodstuff and fat-containing food kinds of stuff, antioxidant releasers or antioxidant packaging films are employed to control the release of oxidized products or the chain reaction of oxygen. ${ }^{14}$ One of the reasons for use of antioxidants in the film layer is to avoid the direct addition of synthetic antioxidants like Butylated Hydroxy Toluene, Butylated Hydroxy Toluene, and TertiaryButyl Hydro Quinone into the food items. The food industry is also looking in such a way as to avoid synthetic additives and to use natural antioxidants in the packages. Antioxidant incorporated food packages are designed to release the antioxidants in a slow and controlled manner so that long-lasting storage can be attained during the storage of foods containing fats and oils. Natural antioxidants like vitamin $\mathrm{E}$ are used for direct incorporation into the food polymer matrix for food active packaging. ${ }^{15}$ One of the advantages of active antioxidant packaging is the absence of the residual effect in the final product. The method of adding antioxidants may be in form of sachets, pads or incorporating in the package labels.

\section{Moisture Absorbers}

Moisture is one of the important spoilage factors in food items. Moisture absorbers are used to arrest the moisture movement and thereby inhibiting the growth of microorganisms in the food item. Moisture is collected in the package due to changes in temperature, drip loss etc. Water is also produced during the breakdown of macromolecules present in the food. ${ }^{16}$ The excessive water can be removed by use of a food package that is highly impermeable to water vapours. Common absorbing systems include a super absorbent polymer present between two layers of microporous or non-woven polymer. Some of the moisture absorbents are polyacrylate salts, carboxymethylcellulose (CMC) and graft copolymers of starch. Another approach for the control of excess moisture in high water activity foods is to intercept the moisture in the vapour phase. This approach allows food packers or even householders to decrease the water activity on the surface of foods by reducing in-pack RH. This can be done by placing one or more humectants between two layers of water-permeable plastic film.

\section{Table 3: Application of Active systems in Foods}

$\begin{array}{ll}\text { Active packages } & \text { Food Applications } \\ \text { Oxygen Scavengers } & \begin{array}{l}\text { Bread, cakes, Pizzas, snack foods and } \\ \text { dried foods }\end{array} \\ \text { Ethylene Scavengers } & \text { Fruits and horticultural products }\end{array}$




\begin{tabular}{|c|c|}
\hline Flavour emitters & $\begin{array}{l}\text { Fruit juices, fried snack foods, dairy } \\
\text { products }\end{array}$ \\
\hline $\begin{array}{l}\mathrm{CO}_{2} \text { scavengers / } \\
\text { emitters }\end{array}$ & Coffee, fresh meats and fish products \\
\hline Preservative releasers & Cheese, meats, snack foods \\
\hline $\mathrm{O}_{2}$ Scavengers & Roasted nuts, Sausages, chocolates \\
\hline Moisture scavengers & All fruits and nuts \\
\hline Antioxidant releasers & Cereals and wines \\
\hline
\end{tabular}

\section{ADVANTAGES}

Active packaging evolved as a potential preservation tool for consumer food items due to its flexibility. They also render sufficient support to the food processors to shape and utilize the technology to the maximum effect, thus supporting the economic health of especially agricultural and horticultural businesses further down the value chain; active packaging can also bring other obvious process benefits to the farmer and industry. Recent developments also show that these methodologies can be combined as Hurdles to increase the preservation effect in packed food items.

\section{DRAWBACKS}

Although active packaging systems eliminate the direct incorporation of additives into food, there are certain limitations with the system. The risk of accidental breakage which can lead to consumption of the content (sachets/pads) along with the food is the one major disadvantage in sachetbased active packaging technologies. ${ }^{17}$ Undesirable vapour formations occur in certain Active Packaging systems involving hormone emitters. After the end-user, the recyclability of the active packages is a question mark. Proper recycling methodologies should be employed to address this issue. Although the efficiency and no contact preservation is established, the cost of active packages is a little higher than the conventional package system due to the additional incorporation. ${ }^{18}$ The polymer and film should be standardized and suitable compatibility to both must be established to obtain the desired result.

\section{FUTURE PROSPECTS IN THE FOOD INDUSTRY}

As the manufacturing sector is gearing up for industry 4.0, these types of packaging technologies must be implemented in all food products for a synergistic transformation of the food industry. One of the important goals of active packaging is to enhance the preservation of the contained food and beverage products through non-contact mode. ${ }^{19}$ Standardized active packages should be designed to boost the packing operation. Proper research should be done on changes during the handling of perishable horticultural commodities like fruits and flowers in the supply chain. More marketoriented subject studies should be given importance so that an effective packaging solution can be achieved. More precise studies on preservation effect, incorporated materials, polymer components need to be studied thereby making the active packaging technology a widely accepted one in the evergreen food industry.

\section{DISCUSSION}

In present day modern food industry, with the development of new preservation techniques to enhance the shelf life of products, the discussed techniques so far have most desirous effect of providing advanced storage techniques to almost all kinds of food products available in the market. The consumer acceptability for these types of packages also growing nowadays, which shows a positive sign for transformation in packaging techniques of foods. Factors like cost of synthesizing active packages, method of preservation/mode of inhibition of spoilage factors are also to be considered from the manufacturer point of view. Thus, if suitably compiled and applied, active packaging will be the most sought method of packaging in the Evergreen food industry.

\section{CONCLUSION}

As discussed, a variety of Active packaging techniques are in use for effective food preservation. The spoilage inhibitory mechanism of various preservatives should be carefully analysed to be used in different food commodities. The concept of Hurdle Technology also can be incorporated to increase the efficiency of food preservation. Importance should be given to no contact preservatives to increase consumer acceptability. To boost the processes food sector, thus a thriving combination of the latest preservation techniques like active and other packing techniques should be given importance.

\section{ACKNOWLEDGEMENTS}

The authors wish to thank Rajalakshmi Engineering College, Chennai for providing an ambient environment and the infrastructure facilities provided at the institute.

Compliance with ethical standards

Conflict of Interest: The authors declare that there is no conflict of interest.

Source of Funding: The source of funding is from the authors themselves 


\section{REFERENCES}

1. Lee DS. Antioxidant packaging system. In Innovations in food packaging, $2^{\text {nd }}$ ed.; J. H., Han, Academic Press: San Diego, USA, 2014:111-131.

2. Labuza TP, Breene W.M., Applications of active packaging for improvement of shelf-life and nutritional quality of fresh and extended shelf-life foods.J. Food Process. Preserv, 1989; 13(1):169.

3. Rooney ML. Overview of Active Packaging. InActive Food Packaging, $1^{\text {st }}$ ed.; M.L.Rooney., Eds. Blackie Academic and Professional: Glasgow, UK, 1995;1-37.

4. Appendini P, Hotchkiss JH. Review of Antimicrobial Food Packaging. Innov. Food Sci. Emerg2002; 3(2) :113-126.

5. Manso S, Becerril R, Nerin C, Gomez-Lus R. Influence of $\mathrm{pH}$ and temperature variations on vapour phase action of an antifungal food packaging against five mould strains. Food Control 2015;47: 20-26.

6. Rivero S., Giannuzzi M.A. and Pinotti A., Controlled delivery of propionic acid from chitosan films for pastry dough conservation. J. of Food Eng. 2013. 116(2): 524-531.

7. Anon., Pursuit of freshness creates packaging opportunities. Jpn. Pack. News 1995; 12: 14-15.

8. Otoni C.G., Trends in antimicrobial food packaging systems: Emitting sachets and absorbent pads. Food Res Int. 2016; 83: 60-73.

9. Fitzgerald M.Non-destructive monitoring of oxygen profiles in packaged foods using phase-fluorimetric oxygen sensor. J. Food Sc.2001; 66(1): 105-110.
10. Day BP, Active packaging. In Food Packaging Technology, 1st ed., R.Cole; D. McDowell; M.J.Kirwan., Eds. CRC Press: Boca Raton, FL, USA, 2003: 282-302

11. Lavoine N., Design, processing and characterization of innovative functional bio-nano-materials for packaging 2013. PhD. Dissertation, Grenoble University, Grenoble, France.

12. Vermeiren L, Devlieghere F, Van Beest M, De Kruijf N. and Debevere J., Developments in the active packaging of foods. Trends Food Sci Technol. 1999; 10(3): 77-86.

13. Labuza TP. An introduction to active packaging for foods. Food Tech 1996.Chicago. 50(4): 68-71.

14. Rooney ML, Active packaging. In The Wiley Encyclopaedia of Packaging Technology, $2^{\text {nd }}$ ed.; A.L.Brody; K.S.Marsh, Eds. John Wiley \& Sons: New York, USA, 1997.

15. Brody AL, Strupinsky ER, Kline LR. Active Packaging for Food Applications. 2001; CRC Press: Boca Raton, FL.

16. Newcorn D, Not just for breakfast anymore. Packaging World. 1997; Feb 28. https://www.packworld.com/design/flexiblepackaging/article/13328948/not-just-for-breakfast-anymore (accessed 28 May 2020).

17. Robertson G.L., Food Packaging Principles and Practice; CRC Press 2013; Boca Raton, FL.

18. Bahrami A, Delshandi R, Assadpour E, Jafari SM, Williams L. Antimicrobial-loaded nanocarriers for food packaging applications.2020; ADV COLLOID INTERFACE,278.

19. Ozdemir M. and Floros J.D., Active food packaging technologies. Critical Reviews in Food Science and Nutritin.2004;44(3): 185-193. 